\title{
Distribution of Sand Flies (Diptera: Psychodidae) at Different Altitudes in an Endemic Region of American Cutaneous Leishmaniasis in the State of Espírito Santo, Brazil
}

\author{
Adelson Luiz Ferreira ${ }^{+}$, Paulo Augusto Sessa, José Benedito Malta Varejão, \\ Aloísio Falqueto
}

\author{
Unidade de Medicina Tropical, Departamento de Patologia, Centro Biomédico, UFES, Av. Marechal Campos \\ 1468, 29040-090 Vitória, ES, Brasil
}

The involvement of different sand fly species in the transmission of American cutaneous leishmaniasis $(A C L)$ at different altitudes was evaluated in the municipality of Afonso Cláudio in the State of Espirito Santo, Brazil, from November 1995 to February 1997. CDC light traps and Shannon traps baited with human volunteers were hung simultaneously at three altitudes of a river valley: (a) 650$750 \mathrm{~m}$ in an area of active ACL transmission; (b) 750-850 $\mathrm{m}$ in a transitional area; and (c) 850-950 $\mathrm{m}$ in an area where no ACL transmission occurred. A total of 13,363 specimens belonging to 28 species was collected. The five most abundant man-biting species were Lutzomyia intermedia, which constituted $24.3 \%$ of the total, Lu. migonei (22.3\%), Lu. whitmani (15.4\%), Lu. fischeri (14.9\%) and Lu. monticola (5.8\%). Analysis of the distribution of these species at the three altitudes provided evidence that Lu. fischeri and Lu. monticola were not involved in ACL transmission, whereas Lu. migonei and Lu. whitmani might act as secondary vectors of Leishmania (Viannia) braziliensis and Lu. intermedia was probably the principal vector of the parasite. These results reinforce those published in the existing literature, which indicate that $\mathrm{Lu}$. intermedia is the main vector of Le. (V.) braziliensis in Southeast Brazil, while Lu. migonei and $\mathrm{Lu}$. whitmani are of secondary importance.

Key words: altitude - sand flies - cutaneous leishmaniasis - Espírito Santo - Brazil

The distribution of American cutaneous leishmaniasis (ACL) is influenced by little-known geographical and climatic factors that determine the distribution of different sand fly vectors, parasites and reservoirs. Tropical climatic conditions and altitudes of up to $800 \mathrm{~m}$ above sea level (asl) favor transmission of Leishmania (Viannia) braziliensis (Mogollón et al. 1977, Bonfante-Garrido 1983, Añez et al. 1988), including in Brazil (Forattini et al. 1972, Aguiar et al. 1987, Azevedo \& Rangel 1991, Passos et al. 1993, Hermeto et al. 1994, Domingos et al. 1998, Gomes \& Neves 1998, Rangel et al. 1999).

In same areas of Northeast and Southeast Brazil that were first colonized by Europeans, the disease is transmitted predominantly in the domestic environment, affecting people of both sexes and of all age groups (Mayrink et al. 1979, Barros et al. 1985, Queiroz et al. 1991, Lainson et al. 1994). Dogs and horses appear to be the domestic reservoirs of

\footnotetext{
${ }^{+}$Corresponding author. Fax: +55-27-335.7287. E-mail: adelsonluiz@escelsanet.com.br Received 28 December 2000 Accepted 24 July 2001
}

Le. (V.) braziliensis, the main etiological agent of ACL in these areas (Falqueto et al. 1986, Aguilar et al. 1989). Among the species of sand flies that have probably adapted to habitats modified by human activities, Lutzomyia intermedia, Lu. whitmani and $\mathrm{Lu}$. migonei, are proven or probable vectors of Leishmania (Rangel et al. 1984, Hoch et al. 1986, Azevedo et al. 1990a, b, Marzochi 1992, Sessa et al. 1994, Marzochi \& Marzochi 1997).

The municipality of Afonso Cláudio in the State of Espírito Santo, Brazil, is an important endemic area of ACL. Sessa et al. (1994) noted that in Liberdade, a village in this municipality, most transmission of the disease was in the peridomicile of houses situated between $600-750 \mathrm{~m}$ asl and none occurred above $850 \mathrm{~m}$. Falqueto (1995) collected five man-biting species of sand flies in the village, i.e., Lu. intermedia, Lu. whitmani, Lu. migonei, Lu. fischeri and Lu. monticola. Although this author considered that most transmission of Le. braziliensis occurred in the peridomiciliary environment, with dogs acting as reservoirs of the parasite, he suggested that a residual sylvatic cycle might also occur, with the armadillo (Euphractus sexcinctus) and the paca (Agouti paca) acting as secondary reservoirs of the parasite. 
Given that man and his domestic animals, as well as wild mammals are present at all altitudes in this area, the absence of ACL above a certain altitude may be attributed to changes in the sand fly fauna. This hypothesis was tested during the present study by systematic sampling of phlebotomines at different altitudes, with the aim at incriminating possible vector species.

\section{MATERIALS AND METHODS}

The village of Liberdade $\left(20^{\circ} 10^{\prime} \mathrm{S} ; 41^{\circ} 05^{\prime} \mathrm{W}\right)$ is located at the head of the Guandu river, a tributary of the Rio Doce in the midwestern region of Espírito Santo, about $100 \mathrm{~km}$ from the Atlantic coast. The area was first colonized about 85 years ago, when coffee plantations were established. Few remnants of the original forest remain and the space between houses in the village is generally occupied by plantations.

The valley in which Liberdade lies presents an altitudinal range of 650-1,000 m over a distance of approximately $6 \mathrm{~km}$, extending in a Southeast-Northeast direction. The relatively short length of the valley made it possible to do simultaneous collections of sand flies at three altitudes. The lowest of these $(650-750 \mathrm{~m}$ asl $)$ is an active transmission area for ACL. The intermediate level (750-850 m) presented fewer cases of the disease and there was no transmission at the head of the valley $(850-950 \mathrm{~m})$.

Three modified Shannon traps (Shannon 1939) of dimensions $1 \mathrm{~m} \mathrm{X} 1 \mathrm{~m} \mathrm{X} 1.9 \mathrm{~m}$ (topped with a overhanging square roof of side $1.6 \mathrm{~m}$ ) and three CDC traps (Sudia \& Chamberlain 1962) were used to sample sand flies. One trap of each type was installed in each of the three altitudes and sampling was performed simultaneously. Shannon traps were installed in the peridomicile of houses while CDC traps were hung in nearby forest, at least $100 \mathrm{~m}$ from the houses. The three volunteers who manned the Shannon traps were randomly assigned to the different altitudes in order to avoid systematic error due to differences in their individual abilities to collect sand flies. Collections were made during the first $4 \mathrm{~h}$ after sunset on 3-5 consecutive nights and repeated at intervals of 4-6 weeks, until each trap had occupied each of the habitats sampled for $100 \mathrm{~h}$.

Clearing and mounting of the insects followed the technique described by Barretto and Coutinho (1940). Specimens were identified according to Young and Duncan (1994).

In order to verify the occurrence of ACL among the human population, the number of cases of the disease recorded in the area between 1993 and 1998 was surveyed by checking local health service archives, the patients having been treated by our group.
The total number of insects collected in the peridomicile or forest during the first $4 \mathrm{~h}$ of darkness at each altitude was considered as the basic sampling unit used in statistical analysis of the results for the most abundant sand fly species.

Levene's homogeneity test and KolmogorovSmirnov's normality test were applied to the data in order to determine whether parametric or nonparametric tests should be applied to the data. Friedman's ANOVA was then applied in multiple samples and, when significant results were obtained, Wilcoxon's test was applied to pairs of samples. Spearman's nonparametric correlation test (Sokal \& Rohlf 1979) was used to evaluate the correlation between the altitudes and the most abundant man-biting sand fly species.

The $\chi^{2}$ (chi-square) test, with binomial approximation and a "post-hoc" Tuckey's test for multiple comparisons of proportions (Zar 1996) were used to study the relative proportions of clinical ACL cases and apparently healthy members of the human population.

\section{RESULTS}

Sand fly sampling was carried out over 50 nights, between November 1995 and February 1997. A total of 13,363 specimens belonging to 28 species was collected. The distribution of these insects at each altitudinal range and in each habitat type is shown in Table I. Among the man-biting species, Lu. intermedia, Lu. migone $i$ and $L u$. whitmani predominated in the peridomicile, Lu. fischeri was equally numerous in peridomiciliary and forest collections, and Lu. monticola was more abundant in the forest.

The altitudinal distributions of the five most abundant Lutzomyia species are shown in the Figure. Both Lu. intermedia and Lu. migonei presented distribution patterns inversely proportional to the altitude. The former was the most abundant species at the altitudes at which active transmission of ACL occurred, its numbers progressively decreasing up to the transmission-free level. Although $L u$. migonei was the second most abundant species at the active transmission level, it was also the second most numerous sand fly at the ACL-free altitude. $\mathrm{Lu}$. whitmani was slightly more numerous at the intermediate altitude than at the level at which active transmission occurred, and was scarce at the transmission-free altitude. Both Lu. fischeri and Lu. monticola showed inverse distribution patterns to those of Lu. intermedia and Lu. migonei. The most abundant species at the highest (transmission-free) altitude was Lu. fischeri and the number of specimens collected at this level was slightly higher than at lower altitudes. At the active transmission level $L u$. monticola was the least abun- 
TABLE I

Phlebotomine sand fly species collected in Liberdade, municipality of Afonso Cláudio, State of Espírito Santo, by Shannon and CDC traps, from November1995 to February 1997, distributed according to altitudes and the catching site

\begin{tabular}{|c|c|c|c|c|c|c|c|c|}
\hline \multirow{3}{*}{ Species } & \multicolumn{6}{|c|}{ Altitudinal range } & \multirow{3}{*}{ Total } & \multirow{3}{*}{$\%$} \\
\hline & \multicolumn{2}{|c|}{$650-750 \mathrm{~m}$} & \multicolumn{2}{|c|}{$750-850 \mathrm{~m}$} & \multicolumn{2}{|c|}{$850-950 \mathrm{~m}$} & & \\
\hline & $\mathrm{Pd}$ & Fr & $\mathrm{Pd}$ & $\mathrm{Fr}$ & $\mathrm{Pd}$ & $\mathrm{Fr}$ & & \\
\hline Lutzomyia intermedia (Lutz \& Neiva) & 2,149 & 189 & 718 & 33 & 159 & 4 & 3,252 & 24.3 \\
\hline Lu. migonei (França) & 1,467 & 194 & 741 & 32 & 524 & 32 & 2,990 & 22.3 \\
\hline Lu. whitmani (Antunes \& Coutinho) & 609 & 288 & 910 & 41 & 193 & 28 & 2,069 & 15.4 \\
\hline Lu. fischeri (Pinto) & 248 & 240 & 307 & 283 & 560 & 366 & 2,004 & 14.4 \\
\hline Lu. monticola (Costa Lima) & 10 & 72 & 24 & 177 & 51 & 451 & 785 & 5.8 \\
\hline Lu. alencari Martins, Souza \& Falcão & 3 & - & 10 & 11 & 4 & 1 & 29 & 0.2 \\
\hline Lu. amarali (Barretto \& Coutinho) & 1 & 3 & 1 & 1 & - & 3 & 9 & $<0.1$ \\
\hline Lu. callipyga Martins \& Silva & - & 9 & - & 1 & - & - & 10 & $<0.1$ \\
\hline Lu. costalimai (Mangabeira) & - & 2 & - & - & - & - & 2 & $<0.1$ \\
\hline Lutzomyia spp. $^{a}$ & 11 & 50 & 7 & 12 & 1 & 1 & 82 & 0.6 \\
\hline Lu. edwardsi (Mangabeira) & 36 & 144 & 5 & 18 & 6 & 12 & 221 & 1.6 \\
\hline Lu. ferreirana (Barretto, Martins \& Pelegrino) & 138 & 181 & 50 & 43 & 27 & 72 & 511 & 3.8 \\
\hline Lu. firmatoi (Barretto, Martins \& Pelegrino) & 243 & 315 & 28 & 23 & 1 & 17 & 627 & 4.6 \\
\hline Lu. hirsuta (Mangabeira) & - & 1 & - & - & - & - & 1 & $<0.1$ \\
\hline Lu. lenti (Mangabeira) & 21 & 7 & 7 & 1 & 9 & - & 45 & 0.3 \\
\hline Lu. matosi (Barretto \& Zago) & - & 2 & - & - & - & - & 2 & $<0.1$ \\
\hline Lu. microps (Mangabeira) & 3 & 9 & 1 & - & - & 2 & 15 & 0.1 \\
\hline Lu. misionensis (Castro) & - & - & - & - & - & 1 & 1 & $<0.1$ \\
\hline Lu. pascalei (Coutinho \& Barretto) & - & 1 & - & 2 & 2 & 3 & 8 & $<0.1$ \\
\hline Lu. pessoai (Coutinho \& Barretto) & 3 & 2 & - & 3 & - & - & 8 & $<0.1$ \\
\hline Lu. pestanai (Barretto \& Coutinho) & - & - & 1 & - & - & - & 1 & $<0.1$ \\
\hline Lu. quinquefer (Dyar) & 406 & 62 & 112 & 14 & 28 & 3 & 625 & 4.6 \\
\hline Lu. sallesi (Galvão \& Coutinho) & 4 & - & 2 & 1 & - & 1 & 8 & $<0.1$ \\
\hline Lu. schreiberi Martins, Falcão \& Silva & 9 & 12 & 5 & 3 & 4 & 4 & 37 & 0.2 \\
\hline Lu. shannoni (Dyar) & - & - & - & - & - & 5 & 5 & $<0.1$ \\
\hline Lu. termitophila Martins, Falcão \& Silva & - & - & - & - & 1 & - & 1 & $<0.1$ \\
\hline Brumptomyia avellari (Costa Lima) & 1 & - & - & - & - & - & 1 & $<0.1$ \\
\hline B. cunhai (Mangabeira) & - & 1 & - & - & - & 1 & 2 & $<0.1$ \\
\hline B. nitzulescui (Costa Lima) & - & 3 & - & - & 1 & - & 4 & $<0.1$ \\
\hline Brumptomyia spp. ${ }^{b}$ & 2 & 4 & 1 & 1 & 1 & - & 9 & $<0.1$ \\
\hline
\end{tabular}

a: Lutzomyia spp. refers to female specimens of the migonei group; $b$ : Brumptomyia spp., to female specimens of the genus Brumptomyia, which can not be distinguished based on morphological characters; Pd: peridomicile; Fr: forest

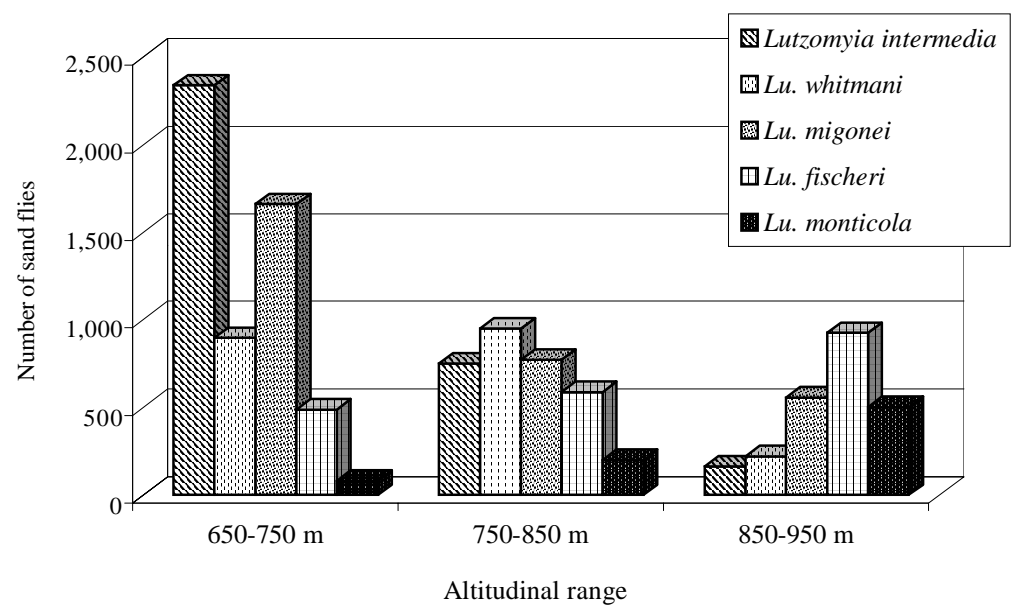

Distribution of the most frequent man-biting sand fly species in relation to altitude, in the Liberdade valley, municipality of Afonso Cláudio, State of Espírito Santo, collected between November 1995 and February 1997. 
dant of man-biting species, its numbers progressively increasing with altitude, until at the highest level it was more numerous than both $L u$. intermedia and $\mathrm{Lu}$. whitmani.

The results of the Levene's homogeneity tests, Kolmogorov-Smirnov's normality test, Friedman's ANOVA multiple samples test, Wilcoxon's sample pairs test and Spearman's nonparametric correlation test, applied to the data on the five most abundant man-biting species are shown in Table II. Among these species, $\mathrm{Lu}$. intermedia presented a significantly negative correlation with altitude. Based on Wilcoxon's test, the number of specimens collected at the lowest altitude was significantly lower than that collected at the intermediate level. A significant drop was also seen between the latter and the highest level. By contrast, the numbers of Lu. migonei presented a significantly negative correlation with increasing altitude between the two lowest levels although the difference between the intermediate and highest levels was not significant according to Wilcoxon's test. A significantly negative correlation was seen between the numbers of Lu. whitmani and increasing altitude for the two highest levels but results were not significant when the lowest and intermediate levels were compared. Lu. monticola showed a significantly positive correlation with increasing altitude only when the lowest and highest levels were compared. Although a positive correlation was observed between numbers of $\mathrm{Lu}$. fischeri sampled and altitude, this was not significant. This was confirmed using Friedman's analysis.

With respect to human disease, 22 cases of ACL were registered in the area from 1993-1998. The distribution of the cases according to the altitude is shown in Table III, and the number of healthy people in each level is represented by present residents who did not acquire the disease. The relative proportions of ACL cases at the three altitudes were significantly different $\left(\chi^{2}=7.78 ; p<0.05\right)$ and according to Tuckey's test, the proportion of ACL cases and apparently healthy individuals in the population only differed significantly between the lowest and highest levels.

\section{DISCUSSION}

The distribution of ACL in the study area seems to be influenced by altitude, the number of cases progressively decreasing from the lowest level, in which active transmission occurs, to the highest altitude, where the disease is absent. Sessa et al. (1994) surveyed residents of the area using the Montenegro skin test, which revealed that 29\% were positive for Leishmania infection. The authors carried out this survey among individuals who lived below $700 \mathrm{~m}$ and no cases of leishmaniasis have been reported above this altitude since then. Other

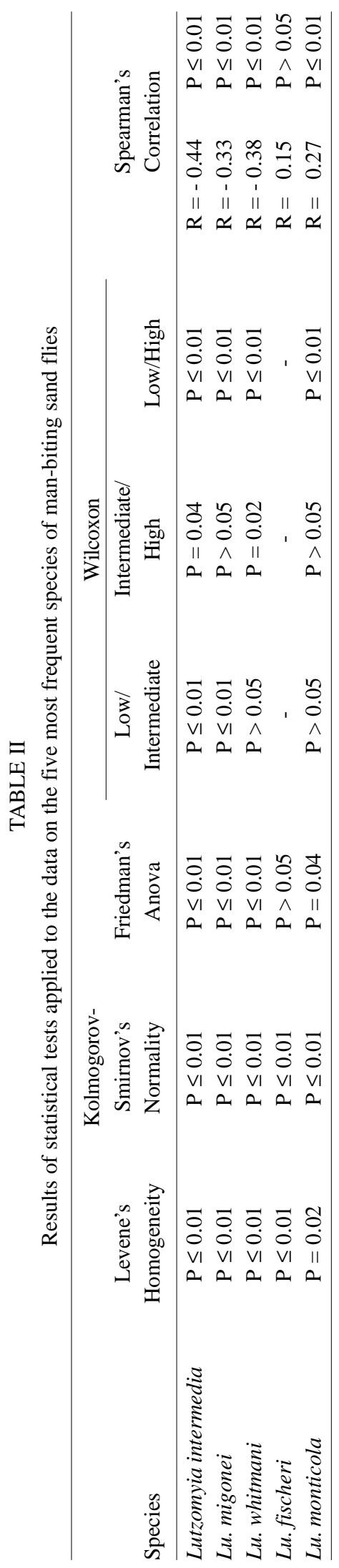




\section{TABLE III}

Numbers (percentages) of clinical cases of American cutaneous leishmaniasis (ACL) and apparently healthy individuals at three altitudinal ranges in the Liberdade valley, municipality of Afonso Cláudio, State of Espírito Santo, 1993-1998

\begin{tabular}{lccr}
\hline & \multicolumn{2}{c}{ Clinical condition } & \\
\cline { 2 - 3 } $\begin{array}{l}\text { Altitude } \\
\text { (m asl) }\end{array}$ & $\begin{array}{c}\text { ACL } \\
\text { cases }\end{array}$ & $\begin{array}{c}\text { Apparently } \\
\text { healthy }\end{array}$ & Total \\
\hline $650-750 \mathrm{~m}^{\mathrm{a}}$ & $19(18.6)$ & 83 & 102 \\
$750-850 \mathrm{~m}^{\mathrm{ab}}$ & $3(6.2)$ & 45 & 48 \\
$850-950 \mathrm{~m}^{\mathrm{b}}$ & 0 & 20 & 20 \\
\hline Total & $22(12.9)$ & 148 & 170 \\
\hline
\end{tabular}

Different letters represent significant differences

authors refer to the occurrence of ACL predominantly at elevations below $800 \mathrm{~m}$ (Bonfante-Garrido 1983, Gomes \& Neves 1998) in tropical and subtropical regions of South America.

ANOVA of the altitudinal distribution of the five most abundant man-biting species indicated the possible role of each in the transmission of $\mathrm{Le}$. (V.) braziliensis to man in the study area.

Among these five species, Lu. monticola appears to be better adapted to higher altitudes where ACL does not occur and therefore is probably not involved in Le. braziliensis transmission. Hermeto et al. (1994) noted a high degree of anthropophily and attraction to light by this sand fly in an ACLendemic area situated at $680 \mathrm{~m}$ asl in the Brazilian State of Minas Gerais, where Lu. monticola comprised $43(39.8 \%)$ of 108 sand flies collected. Falqueto (1995) collected large numbers of this species in the municipality of Venda Nova do Imigrante, Espírito Santo, (750 m asl) an area from which ACL has not been reported. Small numbers of $L u$. monticola have been collected in ACL-endemic areas of the Brazilian States of São Paulo, Minas Gerais and Rio de Janeiro (Aguiar et al. 1987, Passos et al. 1993, Mayo et al. 1998).

The distribution of Lu. fischeri was similar at the three altitudes, suggesting that this species was not involved in the transmission of $L e$. braziliensis, although it is abundant in several areas where the parasite is endemic (Aguiar et al. 1987, Gomes \& Neves 1998).

The uniform distribution of Lu. migonei at the intermediate and high levels indicates that this species may not be an important vector of Le. (V.) braziliensis in the study area. It is noteworthy that large numbers of this sand fly have been collected in domestic environments in several ACL-endemic areas of both Northeast and Southeast Brazil (Azevedo \& Rangel 1991, Falqueto 1995, Gomes \& Neves 1998). The dog, considered to be a reservoir of the parasite by some authors, is highly attractive to $L u$. migonei, so that this species is suspected of maintaining canine ACL (Falqueto et al. 1986, 1991, Falqueto 1995, Marzochi \& Marzochi 1997). There are also records of natural infection of Lu. migonei by Le. (V.) braziliensis in different regions of Brazil (Azevedo et al. 1990a, Queiroz et al. 1991).

It appears that $L u$. whitmani is a secondary vector in the study area, since it occurred in similar numbers at the active and intermediate transmission levels. Although this species showed a low predisposition to enter houses in the Afonso Cláudio area, it was highly attracted to dogs and was the most man-biting species (Falqueto 1995). Working in this same area, Sessa et al. (1994) reported a high prevalence of natural infection by $L e$. (V.) braziliensis among dogs. In addition, there are many records of natural infection of $L u$. whitmani by Le. (V.) braziliensis (Hoch et al. 1986, Azevedo et al. 1990b, Queiroz et al. 1991). This sand fly is therefore considered to be an important peridomiciliary vector in the main endemic areas of ACL in the Northeast of Brazil and in parts of the Southeast region (Mayrink et al. 1979, Azevedo \& Rangel 1991, Lainson et al. 1994). In Espírito Santo, Lu. whitmani is abundant in only six municipalities of the midwest region, including Afonso Cláudio (Falqueto 1995).

Lu. intermedia appears to be the most important vector in the study area, since its decreasing frequency in samples from increasingly higher altitudes, coincides with the distribution of ACL cases. The results of other studies suggest that this species is the main vector of Le. (V.) braziliensis in Southeast Brazil, at least in areas situated below 800 m (Marzochi 1992, Lainson et al. 1994, Rangel et al. 1999). Lu. intermedia is abundant in many endemic areas of ACL, where it has adapted to habitats modified by human activity, showing an increased predisposition to enter houses and bite both man and dogs (Falqueto 1995, Marzochi \& Marzochi 1997, Domingos et al. 1998). There are also records of natural infection with Leishmania (Forattini et al. 1972, Rangel et al. 1984). Lu. intermedia is the most abundant sand fly species in the principal ACL foci of Espírito Santo and other states of Southeast Brazil, providing further evidence of its role in the transmission of Le. (V.) braziliensis (Barros et al. 1985, Falqueto 1995, Gomes \& Neves 1998, Rangel et al. 1999).

Finally, in considering the possible participation of Lu. intermedia, Lu. migonei and Lu. 
whitmani in the transmission of Le. (V.) braziliensis, it should be taken into account that all three species were relatively abundant at the intermediate altitude, where ACL cases are rarely observed. This could be explained by the fact that a poor parasitism was found in dogs infected with Le. (V.) braziliensis, so that higher densities of the vector would be required to maintain the transmission cycle (Falqueto et al. 1986). The results of this study could thus assist in the development of new strategies to control the disease, based on continuous efforts to maintain sand fly populations below levels that permit transmission of $\mathrm{Le}$. (V.) braziliensis.

\section{ACKNOWLEDGMENTS}

To Dr José Luiz Helmer for the revision of the statistical analysis. To Dr Bruce Alexander for English revision.

\section{REFERENCES}

Aguiar GM, Vilela ML, Lima RB 1987. Ecology of the sandflies of Itaguaí, an area of cutaneous leishmaniasis in the State of Rio de Janeiro. Food preferences (Diptera: Psychodidae: Phlebotominae). Mem Inst Oswaldo Cruz 82: 583-584.

Aguilar CM, Rangel EF, Garcia L, Fernandez E, Momen H, Grimaldi Jr G, Vargas Z 1989. Zoonotic cutaneous leishmaniasis due to Leishmania (Viannia) braziliensis associated with domestic animals in Venezuela and Brazil. Mem Inst Oswaldo Cruz 84: $19-28$.

Añez N, Cazorla D, Nieves E, Chataing B, Castro M, De Yarbuh AL 1988. Epidemiologia de la leishmaniasis tegumentaria en Merida, Venezuela. 1 - Diversidad e dispersión de especies flebotomineas en tres pisos altitudinales y su posible role en la transmision de la enfermidad. Mem Inst Oswaldo Cruz 83: 455-463.

Azevedo ACR, Rangel EF 1991. A study of sandfly species (Diptera: Psychodidae: Phlebotominae) in a focus of cutaneous leishmaniasis in the municipality of Baturité, Ceará, Brazil. Mem Inst Oswaldo Cruz 86: 405-410.

Azevedo ACR, Rangel EF, Queiroz RG 1990a. Lutzomyia migonei (França, 1920) naturally infected with peripylarian flagellates in Baturité, a focus of cutaneous leishmaniasis in Ceará State, Brazil. Mem Inst Oswaldo Cruz 85: 479.

Azevedo ACR, Rangel EF, Costa EM, David DJ, Vasconcelos AW, Lopes UG 1990b. Natural infection of Lutzomyia (Nyssomyia) whitmani (Antunes \& Coutinho, 1939) by Leishmania of the braziliensis complex in Baturité, Ceará State, Northeast Brazil. Mem Inst Oswaldo Cruz 85: 251.

Barretto MP, Coutinho JO 1940. Processos de captura, dissecação e montagem de flebótomos. Ann Fac Med Univ S Paulo16: 173-187.

Barros GC, Sessa PA, Mattos EA, Carias VRD, Mayrink W, Alencar JTA, Falqueto A, Jesus AC 1985. Foco de leishmaniose tegumentar americana nos municípios de Viana e Cariacica, estado do Espírito Santo, Brasil. Rev Saúde Públ São Paulo 19: 146-153.

Bonfante-Garrido R 1983. Leishmanias y leishmaniasis tegumentaria en America Latina. Bol Of Sanit Panam 95: 418-424.

Domingos MF, Carreri-Bruno GCC, Ciaravolo RMC, Galati EAB, Wanderley DMV, Corrêa MA 1998. Leishmaniose tegumentar americana: flebotomíneos de área de transmissão, no município de Pedro Toledo, região sul do estado de São Paulo, Brasil. Rev Soc Bras Med Trop 31: 425-432.

Falqueto A 1995. Especificidade Alimentar de Flebotomíneos em Duas Áreas Endêmicas de Leishmaniose Tegumentar no Estado do Espírito Santo, PhD Thesis, Fundação Oswaldo Cruz, Rio de Janeiro, 84 pp.

Falqueto A, Coura JR, Barros GC, Grimaldi Jr G, Sessa PA, Carias VRD, Jesus AC, Alencar JTA 1986. Participação do cão no ciclo de transmissão da leishmaniose tegumentar no município de Viana, estado do Espírito Santo, Brasil. Mem Inst Oswaldo Cruz 81: 155-163.

Falqueto A, Sessa PA, Varejão JBM, Barros GC, Momen H, Grimaldi Jr G 1991. Leishmaniasis due to Leishmania braziliensis in Espírito Santo State, Brazil. Further evidence on the role of dogs as a reservoir of infection for humans. Mem Inst Oswaldo Cruz 86: 499-500.

Forattini OP, Pattoli DBG, Rabello EX, Ferreira AO 1972. Infecção natural de flebotomíneos em foco enzoótico de leishmaniose tegumentar no estado de São Paulo, Brasil. Rev Saúde Públ São Paulo 6: 431433.

Gomes AC, Neves VLFC 1998. Estratégia e perspectivas de controle da leishmaniose tegumentar no estado de São Paulo. Rev Soc Bras Med Trop 31: 553-558.

Hermeto MV, Dias DV, Genaro O, Rotondo-Silva A, Costa CA, Toledo VPCP, Michalick MSM, Williams P, Mayrink W 1994. Outbreak of cutaneous leishmaniasis in the Rio Doce valley, Minas Gerais, Brazil. Mem Inst Oswaldo Cruz 89: 519-521.

Hoch A, Ryan L, Vexenat JA, Rosa ACOC, Barreto AC 1986. Isolation of Leishmania braziliensis braziliensis and others trypanosomatids from Phlebotominae in a mucocutaneous leishmaniasis endemic area, Bahia, Brazil. Mem Inst Oswaldo Cruz 81 (Suppl. I): 62.

Lainson R, Shaw JJ, Silveira FT, Souza AAA, Braga RR, Ishikawa EAY 1994. The dermal leishmaniases of Brazil, with special reference to the eco-epidemiology of the disease in Amazonia. Mem Inst Oswaldo Cruz 89: 435-443.

Marzochi MCA 1992. Leishmanioses no Brasil. As leishmanioses tegumentares. J Bras Med 63: 82-104.

Marzochi MCA, Marzochi KBF 1997. Leishmanioses em áreas urbanas. Rev Soc Bras Med Trop 30 (Suppl. I): $162-165$.

Mayo RC, Casanova C, Mascarini LM, Pignatti MG, Rangel O, Galati EAB, Wanderley DMV, Corrêa FMA 1998. Flebotomíneos (Diptera, Psychodidae) de área de transmissão de leishmaniose tegumentar 
americana no município de Itaupeva, região Sudeste do estado de São Paulo, Brasil. Rev Soc Bras Med Trop 31: 339-345.

Mayrink W, Williams P, Coelho MV, Dias M, Martins AV, Magalhães PA, Costa CA, Falcão AR, Melo MN, Falcão AL 1979. Epidemiology of dermal leishmaniasis in the Rio Doce valley, State of Minas Gerais, Brazil. Ann Trop Med Parasitol 73: 123-137.

Mogollón J, Manzanilla P, Scorza JV 1977. Distribuición altitudinal de nueve especies de Lutzomyia (Diptera: Psychodidae: Phlebotominae) en el Estado Trujillo, Venezuela. Bol Dir Malariol San Amb 17: 206-229.

Passos VMA, Falcão AL, Marzochi MCA, Gontijo CMF, Dias ES, Barbosa-Santos EGO, Guerra HL, Katz N 1993. Epidemiological aspects of American cutaneous leishmaniasis in a periurban area of the metropolitan region of Belo Horizonte, Minas Gerais, Brazil. Mem Inst Oswaldo Cruz 88: 103-110.

Queiroz RG, Vasconcelos IAB, Vasconcelos AWW, Souza RN, Fé Filho NM, David JR 1991. Natural infections in phlebotomine sandflies of an endemic zone for american cutaneous leishmaniasis in Baturité hills, Ceará State, Northeast Brazil. Mem Inst Oswaldo Cruz 86 (Suppl. I): 256.

Rangel EF, Meneses CRV, Cupolillo E, Azevedo ACR, Costa WA, Costa SM 1999. Aspectos da ecologia de Lutzomyia intermedia (Lutz \& Neiva, 1912) e a fauna flebotomínica (Diptera: Psychodidae) em área de transmissão da Leishmania (V) braziliensis no Rio de Janeiro. Rev Soc Bras Med Trop 32 (Suppl. I): 115 .

Rangel EF, Sousa NA, Wermelinger ED, Barbosa AF 1984. Infecção natural de Lutzomyia intermedia Lutz \& Neiva, 1912, em área endêmica de leishmaniose tegumentar no Rio de Janeiro. Mem Inst Oswaldo Cruz 79: 395-396.

Sessa PA, Falqueto A, Varejão JBM, Barros GC 1994. Tentativa de controle da leishmaniose tegumentar americana através do tratamento de cães em área de colonização antiga no estado do Espírito Santo, Brasil. Cad Saúde Públ 10: 457-463.

Shannon R 1939. Methods for collecting and feeding mosquitos in jungle yellow fever studies. Amer $J$ Trop Med 19: 131-140.

Sokal RR, Rohlf 1979. Biometria. Principios y Métodos Estadísticos en la Investigación Biológica, H Blume, Madrid, 832 pp.

Sudia WD, Chamberlain RW 1962. Battery light trap, an improved model. Mosq News 22: 126-129.

Young DG, Duncan MA 1994. Guide to the identification and geographic distribution of Lutzomyia sand flies in Mexico, the West Indies, Central and South America (Diptera: Psychodidae). Mem Amer Ent Inst 54: 1-881.

Zar JF 1996. Biostatistical Analysis, 3rd ed., PrenticeHall Inc, USA, 827 pp. 
